\title{
Performances of anoxic-aerobic membrane bioreactors for the treatment of real textile wastewater
}

\author{
Albahnasawi A.*, Yüksel E., Eyvaz M., Gürbulak E., Polat E. and Arslan S. \\ Gebze Technical University, Department of Environmental Engineering, 41400 Kocaeli, Turkey \\ Received: 15/08/2019, Accepted: 11/10/2019, Available online: 22/10/2019 \\ *to whom all correspondence should be addressed: e-mail: ahmedalbahnasawi@gmail.com \\ https://doi.org/10.30955/gnj.003201
}

\begin{abstract}
Wastewater from textile industry is considered one of the major environmental challenges due to the large volume of highly colored, polluted and toxic effluent. This study investigated the treatability of real textile wastewater by pilot-scale anoxic-aerobic Membrane Bioreactor (MBR) system without sludge wasting for an operation period of 100 days. The proposed system was investigated under different Internal Recycle (IR) ratios and the impact of IR ratio on Total Organic Carbon (TOC), Total Nitrogen (TN) and Color removals were examined. Under IR ratios between anoxic and aerobic tanks of $0.0,0.5$ and 2.0, the respective average removal efficiency of TN was $20.9 \%$, $53.4 \%$ and $71.7 \%$, whereas average color removal of $81 \%$, $85 \%$ and $88 \%$, respectively was noted. The results indicated that increase of recycle ratio from 0.5 to 2.0 enhanced $\mathrm{TN}$ removal to about $71 \%$ and color removal to above $85 \%$. The IR between anoxic and aerobic tanks has a significant role in TN and color removal due to its effect on the development of bacterial communities. On the other hand, the results indicate over 93\% TOC removal, which was independent of IR ratio.
\end{abstract}

Keywords: Anoxic-aerobic bioreactor, de-colorization, internal recycle, textile wastewater.

\section{Introduction}

Besides the massive water consumption by the textile industry, the wastewater from this industry has become a major environmental issue due to its highly polluted and toxic properties (Majewska-Nowak, 2010; Makertihartha et al., 2017). De-sizing, printing, dyeing, sieving scouring, washing, rinsing, bleaching, mercerizing, carbonization, finishing and dyeing are the main processes in textile industry. The water usage depends on fabric type and generated waste streams are loaded with high concentration of residual dye from the dyeing processes (Dilaver et al., 2018). As a consequence of progressively strict restriction on the pollutant content of industrial wastewater, it is urgent to remove hazardous materials from industrial effluents before discharge it to ecosystems (Yin et al., 2018).
Severe environmental problems are presented by colored textile effluents as many kinds of synthetic dyes have been used in textile industry. Theses effluents contain various chemical compositions with high concentration of inorganic and organic compounds. It is reported that more than 100,000 usable textile dyes are available in market, and about $700,000-1,000,000$ tons of pigment are manufactured annually. While 280,000 tons of dye are released from textile manufactory to the environment every year via effluents produced (Samaei, Gato-Trinidad and Altaee, 2018).

The highly colored wastewater has an impact on photosynthetic function in plant. In addition, colored wastewater harmfully affects aquatic life because of low sun light penetration and oxygen utilization. Furthermore, textile wastewater contains metals and chloride that may be harmful to particular aquatic species (Holkar et al., 2016). Also, dye degradation products such as aromatic amines have a toxic and carcinogenic effects on the ecosystem (Alventosa-Delara et al., 2014). Precisely, discharge of highly polluted effluents without decent and sufficient treatment has adversely affected the water bodies, soil and ecosystems (Oliveira et al., 2018).

Different physicochemical treatment methods have been proposed and applied for the treatment of textile wastewater. These include; ion exchange, adsorption, oxidation, coagulation, and membrane separation. Nonetheless, these options are obstructed by technical and economic barriers such as production of harmful byproduct, formation of massive amount of sludge (disposal and handling problems) and high operating/energy costs. It should be noted that most of conventional treatment methods are greatly expensive and need huge amount of energy and dealing with chemicals (Siddique et al., 2017). Among textile wastewater treatment options, biological methods are considered a promising technology to deal with colored wastewater. The biological treatment has many advantages such as eco-friendly, less sludge production, full mineralization, cost effective and less consumption of water (Holkar et al., 2016). 
The anoxic-aerobic system is considered a proper selection for obtaining nitrogen removals by denitrification and nitrification prosses. Integrated anoxic-aerobic treatment systems with membrane processes enhance development of slow-growing bacteria, such as ammonia oxidizing bacteria with capacity to degrade refectory compounds and other organic micropollutants (OPMs) (Su et al., 2014; Ma et al., 2018). The combination of anoxic-aerobic and the Internal recycle (IR) from aerobic to anoxic leads to following: (1) enhanced mixing/mass transfer, (2) dilution of media, (3) transport of dissolved oxygen from aerobic tank and, (4) supply of nitrate (Li et al., 2012; Phan et al., 2016). Moreover, IR between anoxic and aerobic tanks may form conditions that promote development of specific bacterial community distributed between two redox environments, which serve the core function of the integrated anoxicaerobic MBR systems (Luo et al., 2015; Zhang et al., 2018; Xue et al., 2019).

Membrane bioreactor (MBR) are the combination of membrane technology and biological treatment. MBR has been applied in many industrial wastewater treatment systems (Arslan et al., 2016) The main benefits of using MBR for textile effluent treatments are high degree of carbon, nitrogen and color removal, and complete solid removal which results into highly quality of treated wastewater for reuse application (Luong et al., 2016).

Removal of azo dye from wastewater with biological method is a complicated process, including de-colorization and mineralization. However, there is little understanding of the functional microbial community involved in the whole dye degradation process. Studies on the combination of different redox potentials in hybrid systems for color removal are still scarce (Zhu et al., 2018).

In this study, dying process wastewaters from woolen textile sector, which is an important waste source was treated by anoxic-aerobic membrane bioreactor. In line with the aforementioned research gaps, this this study aimed to determine the extent of color removal under various redox conditions common to textile wastewater treatment processes. Integrated anoxic-aerobic MBR was operated to treat real textile wastewater under different redox conditions. Carbon, nitrogen and color removal was assessed in each reactor to determine the effect of different redox regimes. The results of this study point out the importance of redox environment on color removal.

\section{Materials and methods}

\subsection{Material}

The textile wastewater was collected from woolen textile dying factory located in Istanbul-Turkey. The collected wastewater was kept at $4{ }^{\circ} \mathrm{C}$ to eliminate biological growth. A summary of the influent characteristics is shown in Table 1.
Table 1. Characteristics of the Textiles wastewater used in this study

\begin{tabular}{cc}
\hline Parameter & value \\
\hline COD $(\mathrm{mg} / \mathrm{l})$ & 750 \\
\hline BOD $(\mathrm{mg} / \mathrm{l})$ & 350 \\
\hline TOC $(\mathrm{mg} / \mathrm{l})$ & 200 \\
\hline $\mathrm{TN}(\mathrm{mg} / \mathrm{l})$ & 47 \\
\hline $\mathrm{PH}$ & 7.82 \\
\hline Color (ADMI unit) & 480 \\
\hline Conductivity (ms) & 3680 \\
\hline Alkalinity (mg/l) & 435 \\
\hline Chloride (mg/l) & 89.84 \\
\hline Nitrate $-\mathrm{N}(\mathrm{mg} / \mathrm{l})$ & 8 \\
\hline Sulfate $(\mathrm{mg} / \mathrm{l})$ & 394.6 \\
\hline Ammonia-N (mg/l) & 35 \\
\hline TKN $(\mathrm{mg} / \mathrm{l})$ & 39 \\
\hline Organic N (mg/L) & 4 \\
\hline TP $(\mathrm{mg} / \mathrm{l})$ & 0.161 \\
\hline
\end{tabular}

*American Dye Manufacturer's Institute (ADMI) color unit.

\subsection{Experimental setup and procedure}

A batch mode anoxic-aerobic ceramic MBR of $15 \mathrm{~L}$ working volume in each reactor was used in this study (Figure 1). The membrane was composed of flat sheet ceramic membrane module (Chembrane - Denmark) with a nominal pore size of $0.1 \mu \mathrm{m}$ and an effective membrane surface area of $0.528 \mathrm{~m}^{2}$ submerged in an installed aside stream tank. A shift vacuumed/pressured pump (BEM20, Priom Teknik, Turkey) was operated using cycles of $10 \mathrm{~min}$ of suction followed by $2 \mathrm{~min}$ of backwash to prevent clogging on the membrane module. A designated volume of water was recycled from aerobic tank to anoxic tank. Subsequently, the internal recirculation (IR) was calculated as the ratio of volume of the recycled water to the volume of feed. The aerobic reactor and MBR tanks were continuously aerated via air nozzles connected to an air pump. The mixed liquor of the anoxic tank was stirred by an overhead lab mixer (Mtops MS 5010, Kore) to ensure homogeneous distribution in tank. The system was operated at constant flux of $25 \mathrm{LMH}$ and total hydraulic retention time (HRT) of $24 \mathrm{~h}(12 \mathrm{~h}$ for anoxic and $12 \mathrm{~h}$ aerobic), details of the operating cycles are specified in Table 2. Aeration in each reactor was controlled to achieve the desired redox conditions. The dissolved oxygen concentration (DO) in aerobic reactor was maintained at 3-5 $\mathrm{mg} \mathrm{L}^{-1}$ while DO for anoxic reactor was kept at around $0.12 \mathrm{mg} \mathrm{\textrm {L } ^ { - 1 }}$. The Oxidation-reduction potential (ORP) for the anoxic and aerobic reactors were $-115 \pm 25 \mathrm{mV}$ and $130 \pm 16 \mathrm{mV}$, respectively.

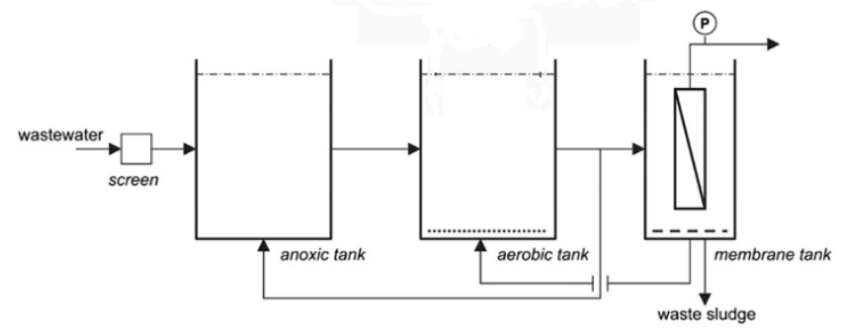

Figure 1. Schematic diagram of the anoxic-aerobic MBR system 


\subsection{MBR operation condition}

The anoxic-aerobic system was initially seeded with activated sludge from a biological nutrient industrial wastewater treatment plant at Dilavos-Turkey. It was operated for a total 100 days, for the initial 33 days the system was operated without internal recycle $(I R=0.0)$ and no sludge withdrawal. This condition allowed sludge acclimatization and stabilization for TOC, color and TN removal. Subsequent to this, the system was operated with $I R=0.5$ for 35 days to investigate the relation between IR, carbon, nitrogen and color removal. In the last 35 days, the system was operated with $I R=2.0$.

Table 2. Operating cycles for anoxic-aerobic MBR

\begin{tabular}{ccc}
\hline Activity & Anoxic & Aerobic \\
\hline Cycle duration $(\mathrm{h})$ & 12 & 12 \\
\hline Filling $(\mathrm{min})$ & 0.5 & 7 \\
\hline Reaction time $(\mathrm{h})$ & 11.125 & 11 \\
\hline Settling time $(\mathrm{min})$ & 45 & 45 \\
\hline Emptying time $(\mathrm{min})$ & 7 & 7 \\
\hline 2.4. Analytical methods & &
\end{tabular}

Samples for analyses were collected from influent, anoxic, aerobic and MBR tanks. Chemical oxygen demand (COD) was measured according to Standard methods(American Public Health Assocation (APHA), 1997). The TOC and TN were analyzed using (IL550 and IL530 TOC-TN Analyze, Hach, Germany), Ammonia was measured using Ammonia-Selective Electrode (Standard method: 4500$\mathrm{NH}_{3}$ D), Thermo Orion model $710 \mathrm{~A}+$ meter and Orion 9512 electrode (Thermo Fisher Scientific, USA). Nitrate was measured using Nitrate Electrode (Standard method: 4500-NO $-\mathrm{N}$ ), the 9707BNWP Nitrate Combination Electrode was used combatable with Thermo Orion 710 At meter (Federation, 1999). Color was measured according to Standard method: 2120 F by using DR 5000, Spectrophotometer, Germany. The analytical procedure was repeated three times and the average data was reported. All chemicals used in the experiments were of analytical grade.

\section{Result and discussion}

This research study was accomplished with real textile wastewater in a pilot-scale plant operated in a batch mode, using anoxic-aerobic membrane bioreactor at $24 \mathrm{~h}$ HRT. The observed concentration of mixed liquor suspended solids (MLSS) was 5.2-5.8 $\mathrm{g} \mathrm{L}^{-1}$ for aerobic tank and 2.5-2.7 $\mathrm{g} \mathrm{L}^{-1}$ for the anoxic tank. The MLVSS/MLSS ratios were stable at $0.68 \pm 0.04$ and $0.71 \pm 0.03$ for the anoxic and the aerobic tanks, respectively. The Mixed liquor $\mathrm{pH}$ for aerobic tank was stable at $8.15 \pm 0.65$ whereas that of anoxic tank was $7.25 \pm 05$.

\subsection{Organic matter removal (TOC)}

In this study, TOC is used as indicator of organic matter contamination. TOC analysis is specific to organic compounds and theoretically measures all the covalently bonded carbon in water. In all the countries, the analysis of TOC is recognized as the most suitable index for the control of civil and industrial wastes (Visco, Campanella and Nobili, 2005). The TOC removal of the integrated anoxic-aerobic MBR during the 100 days operation time is presented in Figure 2. As can be seen, average TOC removal of $93 \%$ (6-22 $\mathrm{mg} / \mathrm{L}$ residual TOC) was observed in the system, far below the Turkish national discharge standard of effluent from Textile industry (COD < $200 \mathrm{mg}$ $\left.\mathrm{L}^{-1}\right)$. The results also indicate potential of wastewater treatment for reuse applications, if appropriate farther refining such as nanofiltration and reverse osmosis are applied. Notably, the aerobic tank served as an efficient treatment step for TOC with a small variation in TOC removal with IR ratios due to the dilution effects. In addition, effluent TOC concentration was not affected by increase in IR ratio. This indicates stability of the system for TOC removal. The results of this study are in agreement with those reported by Sun et al., in which over $85 \%$ removals of organic matter were recorded for treatment of textile auxiliary's wastewater under IR of 0.5 , 1.5 and 2.5. Moreover, in the same study, Sun et al. observed that effluent COD concentration was not affected when the recycle ratio was increased from about 0.5 to 2.5 (Sun et al., 2015).

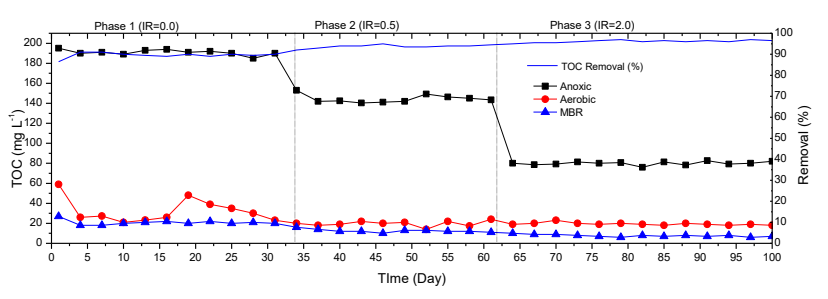

Figure 2. TOC concentration and removal efficiency over the entire operation period of the anoxic-aerobic MBR

\subsection{Nitrogen removal}

An overview of TN concentration and removal efficiency for the entire operation period is given in Figure 3. The 100-day operation period was divided into three phases according to the IR ratio used. Phase one lasted for 31 days with zero IR. Phase two lasted 35 days with 0.5 IR ratio and phase three lasted 35 days with 2.0 IR ratio. To gain a better insight into nitrogen removal, analyses were done for $\mathrm{TN}, \mathrm{NH}_{3}-\mathrm{N}$ and $\mathrm{NO}_{3}{ }^{-} \mathrm{N}$ concentrations in all the three phases. Stable performance of $\mathrm{NH}_{3}-\mathrm{N}$ and $\mathrm{TN}$ removal from anoxic-aerobic MBR was observed 7 days after start of operation. As shown in Figure 4, nitrification occurred in the aerobic reactor and the effluent $\mathrm{NH}_{3}-\mathrm{N}$ concentration was $7 \mathrm{mg} \mathrm{L}^{-1}$, which demonstrates that $94 \%$ of $\mathrm{NH}_{3}-\mathrm{N}$ was oxidized. During the first Phase, with an average influent TN concentration of $35 \mathrm{mg} \mathrm{L}^{-1}-\mathrm{N}$, removal efficiency of about $20 \%$ was recorded. TN concentration in the effluent from anoxic reactor, aerobic reactor and MBR tank were $40 \pm 2,38 \pm 2$ and $36 \pm 2 \mathrm{mg} \mathrm{L}^{-1}$, respectively, indicating that $\mathrm{TN}$ was mainly removed in anoxic reactor as $\mathrm{NO}_{3}^{-}-\mathrm{N}$. To improve $\mathrm{TN}$ removal, IR was increased from 0.0 to 0.5 which ensured increased nitrate load to the anoxic reactor in Phase 2 (32-61 days). When $\mathrm{NH}_{3}-\mathrm{N}$ concentration of anoxic reactor was only $23 \pm 2 \mathrm{mg} \mathrm{L}^{-1}$ because of the dilution of the raw wastewater, the effluent concentration from recycled mixed liquor from 
aerobic reactor was $3 \mathrm{mg} \mathrm{L}^{-1}$. During stable operation, the final effluent concentration of $\mathrm{NH}_{3}-\mathrm{N}$ in the aerobic reactor remained less than $2 \mathrm{mg} \mathrm{L}^{-1}$, while the $\mathrm{NO}_{3}^{-}-\mathrm{N}$ concentration averaged $20 \mathrm{mg} \mathrm{L}^{-1}$. TN concentration in the effluent from anoxic reactor, aerobic reactor and MBR tank were $28 \pm 2,26 \pm 3$ and $20 \pm 4 \mathrm{mg} \mathrm{L}^{-1}$, respectively. Despite increasing IR ratio to 0.5 in phase 2 , the observed TN removal efficiency at this phase was around $53 \%$. Finally, increasing the IR ratio to around 2.0 in phase 3 (62nd-100th day) resulted into effluent $\mathrm{NH}_{3}-\mathrm{N}$ concentration in the anoxic-aerobic MBR of less than 1 $\mathrm{mg} / \mathrm{L}$ and the TN concentration in the final effluent of $12 \pm 3 \mathrm{mg} \mathrm{L}^{-1}$. This suggests that TN mainly reduced in anoxic and aerobic reactors due to the removal of recycled $\mathrm{NO}_{3}-\mathrm{N}$. The results indicated that increase of recycle ratio from 0.5 to 2.0 enhanced the percentage of TN removal to about $71 \%$.

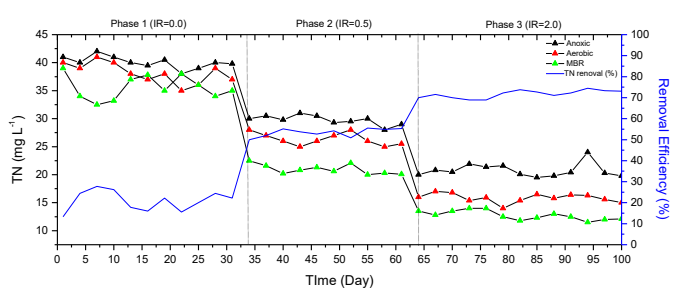

Figure 3. TN concentration and removal efficiency over the entire operation period of the anoxic-aerobic MBR

It is well-known that for a pre-denitrification system, the internal mixed liquor recycle flow from the aerobic to the anoxic zones plays an important role that affects the TN removal efficiency. Tan and $\mathrm{Ng}$ reported $\mathrm{TN}$ removal efficiencies of domestic wastewater as $57 \%, 74 \%, 72 \%$ and $61 \%$ for recycle ratio of $1,3,5$ and 10 , respectively (Tan and Ng, 2008). Similarly, Baeza et al. reported TN removal efficiencies of $67 \%, 72 \%$ and $80 \%$ for the recycle ratio of 0,2 and 5, respectively (Baeza, Gabriel and Lafuente, 2004). Under anoxic conditions, performance of denitrification could be enhanced by the availability of easily biodegradable organic matter, enough HRT and low dissolved oxygen (DO) concentration in the recycle flow. In the present study, HRT of $12 \mathrm{~h}$ was maintained in the anoxic reactor for all the three phases, which is sufficient for anoxic denitrification (Kim et al., 2008).

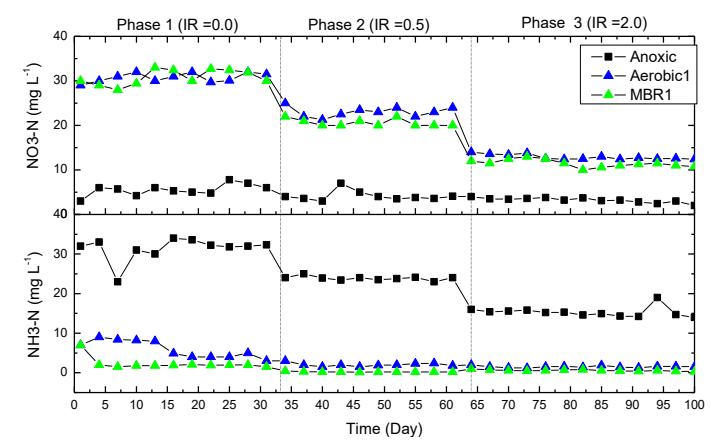

Figure 4. $\mathrm{NO}_{3}-\mathrm{N}$ and $\mathrm{NH}_{3}-\mathrm{N}$ concentration over the entire operation period of the anoxic-aerobic MBR

\subsection{Color removal}

The differences in the bacterial communities developed under conditions with/without IR not only explain the variations in the nutrient removal performance by the system (Section 3.2) but also provide insights into the variation in color removal under different redox conditions as showed in Figure 5. The average color removal efficiencies in the integrated anoxic-aerobic MBR system were $81 \%, 85 \%$, and $88 \%$ for (IR $=0.0)$, ( $I R=0.5)$, and $(I R=2.0)$, respectively, resulting in high average system efficiencies. The color removal ranged from $78 \%$ to $82 \%$ for IR ratio of 0.0 . Increasing the IR ratio to 0.5 and 2.0 resulted into $3 \%$ and $6 \%$, respective enhancement in cooler removal. The enhancement in color removal under various IR between anoxic and aerobic reactors could be attributed to the development of an environment suitable for bacterial community shared between these two redox regimes, and possible excretion of diverse enzymes responsible for the core function of the integrated anoxicaerobic MBR system (Phan et al., 2016; Mallick and Chakraborty, 2019). In addition, in anoxic treatment, due to the low level of oxygen present in the system, an alternate electron acceptor is required. The azo bond can act as this electron acceptor, which results in decolorization owing to cleavage of the azo bond. integrated anoxic-aerobic treatment processes can remove reactive azo dye color from wastewater more effectively than traditional aerobic processes. A biomass can be developed that is viable and effective in both anoxic and aerobic environments. The anoxic phase exhibits both a higher percentage color removal and a greater rate of color removal than the aerobic phase. (Khehra et al., 2006; Rass-Hansen et al., 2007; Venkata Mohan, Rao and Sarma, 2007).

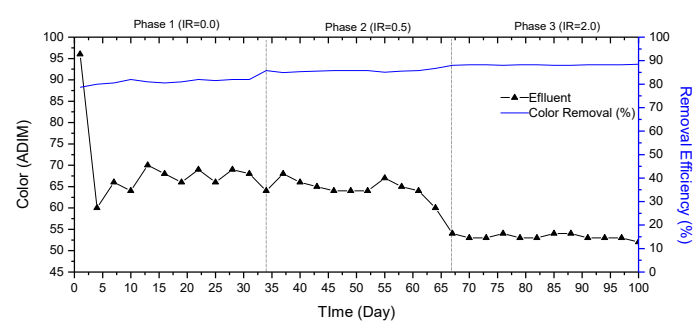

Figure 5. Color removal efficiency over the entire operation period of the anoxic-aerobic MBR

\section{Conclusion}

Simultaneous organic matter, TN and color removal in textile wastewater treatment by an integrated anoxicaerobic MBR was examined. The study demonstrates that a system comprising of an anoxic-aerobic bioreactor and ceramic membrane is effective for textile wastewater treatment. Organic matter removal was generally higher than 93\%. The use of an anoxic reactor was effective in TN and color removals which reached values higher than $70 \%$ and $85 \%$, respectively. The IR between anoxic and aerobic tanks demonstrated a significant role in $\mathrm{TN}$ and color removal due to development of bacterial community 
under various IR. Nevertheless, the TOC concentration was not affected by IR ratio. Further research is needed to investigate the bacterial communities responsible for color degradation under different IR ratios, in addition, investigation of IR effect on elimination of generated aromatic amines is required.

\section{Acknowledgements}

I gratefully acknowledge the funding received towards my $\mathrm{PhD}$ from Turks Abroad and Related Communities (YTB). The authors would like to thank Mr. Varol Çetinkaya (Füzyon Su Teknolojileri Ve Otomasyon San. Tic.Ltd. Sti) for providing the anoxic-aerobic MBR pilot scale system. Thanks to Prof. Ebubekir Yuksel for his encouragement and supervisory role and also all friends working at (SUMER) in Gebze technical university.

\section{References}

Alventosa-Delara E. et al. (2014), Ultrafiltration ceramic membrane performance during the treatment of model solutions containing dye and salt, Separation and Purification Technology, Elsevier B.V., 129, pp. 96-105. doi: 10.1016/j. seppur.2014.04.001.

American Public Health Assocation (APHA) (1997), 4-108 Inorganic Nonmetals (4000), APHA 4500- $\mathrm{NH}_{3}$ Nitrogen Ammonia, (4000), 108-117.

Arslan S., Eyvaz M., Gürbulak E. and Yüksel E. (2016), A Review of State-of-the-Art Technologies in Dye-Containing Wastewater Treatment - The Textile Industry Case. Textile Wastew, Textile Wastewater Treatment, 1-28. doi: 10.5772/64140.

Baeza J.A., Gabriel D. and Lafuente J. (2004), Effect of internal recycle on the nitrogen removal efficiency of an anaerobic/anoxic/oxic (A2/O) wastewater treatment plant (WWTP), Process Biochemistry, 39(11), 1615-1624. doi: 10.1016/S0032-9592(03)00300-5.

Dilaver M. et al. (2018), Hot wastewater recovery by using ceramic membrane ultrafiltration and its reusability in textile industry, Journal of Cleaner Production, 171, 220-233. doi: 10.1016/j.jclepro.2017.10.015.

Federation W.E. (1999), Standard Methods for the Examination of Water and Wastewater Part 1000 Standard Methods for the Examination of Water and Wastewater.

Holkar C.R. et al. (2016), A critical review on textile wastewater treatments: Possible approaches, Journal of Environmental Management, Elsevier Ltd, 182, 351-366. doi: 10.1016/j. jenvman.2016.07.090.

Khehra M.S. et al. (2006), Biodegradation of azo dye C.I. Acid Red 88 by an anoxic-aerobic sequential bioreactor, Dyes and Pigments, Elsevier, 70(1), 1-7. doi: 10.1016/J.DYEPIG.2004. 12.021.

Kim Y.M. et al. (2008), Effect of HRT on the biological predenitrification process for the simultaneous removal of toxic pollutants from cokes wastewater, Bioresource Technology, Elsevier, 99(18), 8824-8832. doi: 10.1016/J.BIORTECH.2008. 04.050 .

Li X. et al. (2012), In situ investigation of fouling behavior in submerged hollow fiber membrane module under subcritical flux operation via ultrasonic time domain reflectometry, Journal of Membrane Science, Elsevier B.V., 411-412, 137-145. doi: 10.1016/j.memsci.2012.04.024.

Luo Y. et al. (2015), Evaluation of micropollutant removal and fouling reduction in a hybrid moving bed biofilm reactor- membrane bioreactor system, Bioresource Technology, Elsevier Ltd, 191, 355-359. doi: 10.1016/j.biortech.2015. 05.073 .

Luong T.V. et al. (2016), Membrane Bioreactor and Promising Application for Textile Industry in Vietnam, Procedia CIRP, Elsevier B.V., 40, 419-424. doi: 10.1016/j.procir.2016.01. 083.

Ma J. et al. (2018), Applications of membrane bioreactors for water reclamation: Micropollutant removal, mechanisms and perspectives, Bioresource Technology, Elsevier, 269(June), 532-543. doi: 10.1016/j.biortech.2018.08.121.

Majewska-Nowak K.M. (2010), Application of ceramic membranes for the separation of dye particles, Desalination, Elsevier, 254(1-3), 185-191. doi: 10.1016/J.DESAL.2009.11. 026.

Makertihartha I.G.B.N. et al. (2017), Dyes removal from textile wastewater using graphene based nanofiltration, p. 110006. doi: 10.1063/1.4982336.

Mallick S.K. and Chakraborty S. (2019), Bioremediation of wastewater from automobile service station in anoxicaerobic sequential reactors and microbial analysis, Chemical Engineering Journal, Elsevier, 361(October 2018), 982-989. doi: 10.1016/j.cej.2018.12.164.

de Oliveira G.A.R. et al. (2018), A test battery for assessing the ecotoxic effects of textile dyes, Chemico-Biological Interactions, Elsevier, 291(June), 171-179. doi: 10.1016/j.cbi. 2018.06.026.

Phan H.V. et al. (2016), Bacterial community dynamics in an anoxic-aerobic membrane bioreactor - Impact on nutrient and trace organic contaminant removal, International Biodeterioration and Biodegradation, Elsevier Ltd, 109, 6172. doi: 10.1016/j.ibiod.2016.01.002.

Rass-Hansen J. et al. (2007), Perspective Bioethanol: fuel or feedstock, Journal of Chemical Technology and Biotechnology, 82(August 2006), 329-333. doi: 10.1002/jctb.

Samaei S.M., Gato-Trinidad S. and Altaee A. (2018), The application of pressure-driven ceramic membrane technology for the treatment of industrial wastewaters - A review, Separation and Purification Technology, Elsevier, 200(February), 198-220. doi: 10.1016/j.seppur.2018.02.041.

Siddique K. et al. (2017), Textile Wastewater Treatment Options: A Critical Review Textile Wastewater Treatment Options: A Critical Review, (May), doi: 10.1007/978-3-319-55423-5.

Su L. et al. (2014), Effect of redox conditions on pharmaceutical loss during biological wastewater treatment using sequencing batch reactors, Journal of Hazardous Materials, Elsevier B.V., 282, 106-115. doi: 10.1016/j.jhazmat.2014.08. 002.

Sun F. et al. (2015), Organics and nitrogen removal from textile auxiliaries wastewater with A2O-MBR in a pilot-scale, Journal of Hazardous Materials, Elsevier B.V., 286, 416-424. doi: 10.1016/j.jhazmat.2015.01.031.

Tan T.W. and Ng H.Y. (2008), Influence of mixed liquor recycle ratio and dissolved oxygen on performance of predenitrification submerged membrane bioreactors, Water Research, 42(4-5), 1122-1132. doi: 10.1016/j.watres.2007. 08.028 .

Venkata Mohan S., Rao N.C. and Sarma P.N. (2007), Simulated acid azo dye (Acid black 210) wastewater treatment by periodic discontinuous batch mode operation under anoxicaerobic-anoxic microenvironment conditions, Ecological 
Engineering, Elsevier, 31(4), 242-250. doi: 10.1016/J. ECOLENG.2007.07.003.

Visco G., Campanella L. and Nobili V. (2005), Organic carbons and TOC in waters: An overview of the international norm for its measurements, Microchemical Journal, 79(1-2), 185191. doi: 10.1016/j.microc.2004.10.018.

Xue F. et al. (2019), Residual micro organic pollutants and their biotoxicity of the effluent from the typical textile wastewater treatment plants at Pearl River Delta, Science of the Total Environment, Elsevier B.V., 657, 696-703. doi: 10.1016/j. scitotenv.2018.12.008.

Yin Z. et al. (2018), Effect of integrated pretreatment technologies on RO membrane fouling for treating textile secondary effluent: Laboratory and pilot-scale experiments, Chemical Engineering Journal, Elsevier, 332(September 2017), 109-117. doi: 10.1016/j.cej.2017.09.059.

Zhang D. et al. (2018), Fate and behavior of dissolved organic matter in a submerged anoxic-aerobic membrane bioreactor (MBR), Environmental Science and Pollution Research, Environmental Science and Pollution Research, 25(5), 42894302. doi: 10.1007/s11356-017-0586-x.

Zhu Y. et al. (2018), Performances and structures of functional microbial communities in the mono azo dye decolorization and mineralization stages, Chemosphere, Elsevier Ltd, 210, 1051-1060. doi: 10.1016/j.chemosphere.2018.07.083. 